\title{
Medulläres Schilddrüsenkarzinom
}

Herausgegeben von

Joachim Feldkamp · Werner A. Scherbaum · Matthias Schott

Walter de Gruyter

Berlin · New York 2002 


\section{Herausgeber}

\section{PD Dr. med. Joachim Feldkamp}

Prof. Dr. med. Werner A. Scherbaum

Dr. med. Matthias Schott

\section{Klinik für Endokrinologie}

Universitätsklinik der Heinrich-Heine-Universität Düsseldorf

Moorenstraße 5

40225 Düsseldorf

\section{Die Deutsche Bibliothek - CIP-Einheitsaufnahme}

Medulläres Schilddrüsenkarzinom / hrsg. von Joachim Feldkamp .... -

Berlin ; New York : de Gruyter, 2002

ISBN 3-11-017366-2

(C) Copyright 2001 by Walter de Gruyter GmbH \& Co. KG, 10785 Berlin.

Dieses Werk einschließlich aller seiner Teile ist urheberrechtlich geschützt. Jede Verwertung außerhalb der engen Grenzen des Urheberrechtsgesetzes ist ohne Zustimmung des Verlages unzulässig und strafbar. Das gilt insbesondere für Vervielfältigungen, Übersetzungen, Mikroverfilmungen und die Einspeicherung und Verarbeitung in elektronischen Systemen.

Der Verlag hat für die Wiedergabe aller in diesem Buch enthaltenen Informationen (Programme, Verfahren, Mengen, Dosierungen, Applikationen etc.) mit Autoren und Herausgebern große Mühe darauf verwandt, diese Angaben genau entsprechend dem Wissensstand bei Fertigstellung des Werkes abzudrucken. Trotz sorgfältiger Manuskriptherstellung und Korrektur des Satzes können Fehler nicht ganz ausgeschlossen werden. Autoren bzw. Herausgeber und Verlag übernehmen infolgedessen keine Verantwortung und keine daraus folgende oder sonstige Haftung, die auf irgendeine Art aus der Benutzung der in dem Werk enthaltenen Informationen oder Teilen davon entsteht.

Die Wiedergabe von Gebrauchsnamen, Handelsnamen, Warenbezeichnungen und dergleichen in diesem Buch berechtigt nicht zu der Annahme, dass solche Namen ohne weiteres von jedermann benutzt werden dürfen. Vielmehr handelt es sich häufig um gesetzlich geschützte, eingetragene Warenzeichen, auch wenn sie nicht eigens als solche gekennzeichnet sind.

Textkonvertierung: Ingrid Ullrich, Berlin - Druck: Gerike GmbH, Berlin - Buchbinderische Verarbeitung: Lüderitz \& Bauer GmbH, Berlin - Umschlagentwurf: Rudolf Hübler, Berlin 